\title{
A Matrix Approach to the Customer-oriented Product Design
}

\author{
Ming-Chyuan Lin* and Lung-An Chen \\ Department of Industrial Design, College of Planning and Design, National Cheng Kung University, Tainan, Taiwan 701
}

\begin{abstract}
A customer-oriented product designer must rely on many types of information, including customer-product requirements and design developments in the related fields. Concurrent engineering applications in product design problems will help designers to systematically consider relevant design information and make the most effective use of the time they devoted to the design process. Even though many new principles and approaches have been introduced to help designers to identify the relationship between customer requirements and design characteristics and solve complex design problems, they seldom focus on the generation of feasible design alternatives. This drawback greatly affects customer-oriented product design development.

This research introduces a matrix approach that can efficiently generate feasible design alternatives for a specific set of customer requirements. The procedures developed for this matrix approach is based on a congruent matrix multiplication operator, component design strategy, and relational database system. A sport shoe design is used as an example to help explain the development of these procedures. The results indicate that the matrix approach will assist designers in linking customer requirements with products during design development and even enhance the efficiency of concurrent engineering.
\end{abstract}

Key Words: matrix approach, customer-oriented product design, relational database system, component design strategy, congruent matrix multiplication operator.

\section{Introduction}

Product design is a creative process that integrates abstract design components into a complete specification of product characteristics that satisfy customer requirements. The growth of manufacturing technology has long been more advanced than product design, but product design plays an important role in developing manufacturing systems for improving manufacturability, quality, and cost reduction [1,2]. Because product design is a very complicated task, many companies have tried to use computer-aided design (CAD), computeraided manufacturing (CAM), computer-integrated manufacturing (CIM) systems and computer-based information systems in the design process to enhance the efficiency of their product design efforts [3-5]. These efforts have been directed toward the integration of design and manufacturing related techniques into the concurrent engineering (CE) concept [6]. Prasad [6] developed an integrated product development (IPD) system that emphasized the importance of customer requirements in CE. As competition in the world market has increased, many manufacturing industries have

*Author to whom correspondence should be addressed.

E-mail: minglin@mail.ncku.edu.tw gradually changed their production policy into mass customization to create a crucial connection between the customers' requirements and products [7]. Mousavi et al. [8] presented a customer optimization route and evaluation (CORE) model that translated the customers' qualitative requirements into design attributes for customer-oriented design. Chen et al. [9] proposed a prototype customer-oriented product concept formation system that involved system, technology, and human levels in the product development. Ulrich and Eppinger [10] mentioned that unlike technology-driven products, customer-driven product design should work closely with marketing to identify the proper customer requirements. However, most designers have their own unique biases that produce a multitude of design alternatives by different designers to meet similar design criteria. This will significantly affect the processes used in evaluating design alternatives and may also require a considerable amount of time.

In general, product design is a hybrid activity that is based primarily on the customer requirements to be met by that product. The designer must clearly define these customer requirements and design characteristics and produce an appropriate design solution [11]. Historically, a combination of personal observations such as checklist, literature search, analogies and attribute lists, and intuitive findings such as brainstorming, synetics, the Delphi method and morphological 
box, and systematic analysis such as market research, design catalogs and study of physical processes, have been used to help designers identify and select customer requirements and design characteristics [12-14]. Tseng and Jiao [15] introduced a product definition methodology for functional requirements (PDFR) incorporating a requirement management database (RMDB) to improve product definition during the design and redesign processes. These customer requirements and design characteristics should then be restructured or grouped to express their relationships to determine the design approach that will make the product design more successful. A popular technique, quality function deployment (QFD) in CE can provide designers with a way to explore the relationship between the customer's voice and the design characteristics [16]. Suh [17] introduced the axiomatic design concept and suggested that the designer begin the design process by defining the functional requirements for the design problem at hand; such that the functional requirements are independent of each other and their integration is not redundant. Jiao and Zhang [18] further proposed an association rule mining system (ARMS) for product portfolio identification that entailed a mapping process from the customer needs to the functional requirements. Although the QFD techniques, axiomatic design and related research theories such as concurrent function deployment (CFD) [19] are very helpful for designers in considering customer requirements, they do not deal with the generation of feasible design alternatives. Generating feasible design alternatives in most design activities is still heavily reliant on the designer's subjective opinion, experience, and knowledge. This greatly affects the development of design automation.

Systematic approaches to the product design process will assist the designer in identifying design problems, design criteria, and enhance the evaluation effectiveness of the final design solution [20]. Using mathematical matrix properties can even permit the designer to efficiently apply computer technologies in design process development. In most design processes, it is possible to represent the customer requirements and design problem specification solutions in vector form. The objective of this research is to develop a matrix approach that assists the designer in generating feasible design alternatives for specific sets of customer requirements. The proposed approach uses the component design strategy concept [21] and relational database system [22,23] to manipulate previous information and newly developed system components. The system identifies the relationship between input customer requirements and output design parameters. Note that the proposed matrix approach will be applied to consumer products. The matrix approach applicability is demonstrated in choosing a sport shoe design. The final system will easily assist designers or manufacturers in closely linking the product design process with CIM systems.

\section{The Conceptual Matrix Approach}

As mentioned above, the matrix approach will apply matrix properties to eliminate infeasible design component combinations and generate feasible design alternatives. A coding system will be developed to manipulate geometric parameter information and to provide an interface between the product design and $\mathrm{CAD} / \mathrm{CAM} / \mathrm{CIM}$ systems [3].

The input and output parameters used in developing the matrix approach will be modified to provide two types of information: (1) text information using semantic words or sentences to express meaning, and (2) geometric forms to represent the product components. Based on the revised input and output parameter characteristics and their design relationships, the matrix approach steps are developed as follows:

Step 1. Develop an input/output interaction matrix

Let the set of design input parameters that represent the customer requirements be denoted as $\left[\mathrm{X}_{1}, \mathrm{X}_{2}, \ldots\right.$, $\left.\mathrm{X}_{m-1}, \mathrm{X}_{m}\right]$ and the set of design output parameters that represent the design solution be denoted as $\left[Y_{1}, Y_{2}, \ldots\right.$, $\left.\mathrm{Y}_{n-1}, \mathrm{Y}_{n}\right]$. The set of possible values for each design input parameter is denoted as $\mathrm{U}_{p, q_{p}}$; where $p=1,2, \ldots, m$ corresponds to the design input parameters $\mathrm{X}_{1}, \mathrm{X}_{2}$, $\ldots, \mathrm{X}_{m} ;$ and $q_{p}=1,2, \ldots, \mathrm{A}_{p}$, where $\mathrm{A}_{1}, \mathrm{~A}_{2}, \ldots, \mathrm{A}_{m}$ represent the number of possible values for the design input parameters $\mathrm{X}_{1}, \mathrm{X}_{2}, \ldots, \mathrm{X}_{m}$, respectively. The set of possible values for each design output parameter is denoted as $\mathrm{V}_{i, j_{i}}$; where $i=1,2, \ldots, n$ corresponds to design output parameter $\mathrm{Y}_{1}, \mathrm{Y}_{2}, \ldots, \mathrm{Y}_{n}$, and $j_{i}=1$, $2, \ldots, \mathrm{B}_{i}$, where $\mathrm{B}_{1}, \mathrm{~B}_{2}, \ldots, \mathrm{B}_{n}$ represent the number of possible values for design output parameter $\mathrm{Y}_{1}, \mathrm{Y}_{2}$, $\ldots, \mathrm{Y}_{n}$, respectively. The input/output matrix is then represented as

$$
\begin{aligned}
& \text { Design output parameters } \\
& \mathrm{Y}_{1} \mathrm{Y}_{2} \cdot \cdot \mathrm{Y}_{n}
\end{aligned}
$$

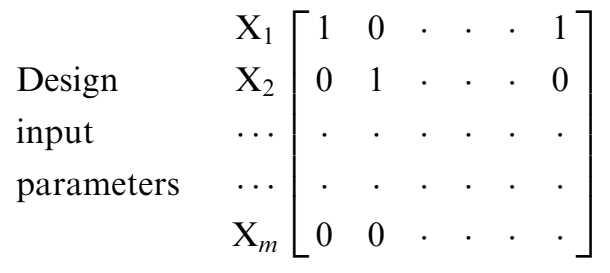

A design input/output parameters interaction matrix will be developed based on the sport shoe design research literature, expert opinion, and product performance characteristics. The matrix will document relationships among design input and output parameters. 
Step 2. Generate a feasible choice matrix

The procedure to be developed will link the customer's requirements in terms of values for the set of design input parameters to a matrix array called the choice matrix. This choice matrix array will have the number of rows as the number of selected design output parameters. The number of columns in this array will equal the number of each row of design output parameter values. The typical element in a choice matrix will have the following value:

$\mathrm{C}_{i, j}=1$ if the design output parameter value ' $j$ ' in design output parameter ' $i$ ' is selected as a component of a pair of shoes proposed to satisfy the customer's requirements, and

$\mathrm{C}_{i, j}=0$ if the design output parameter value ' $j$ ' in design output parameter ' $i$ ' will not be a part of the proposed pair of shoes.

Note that in any feasible choice matrix

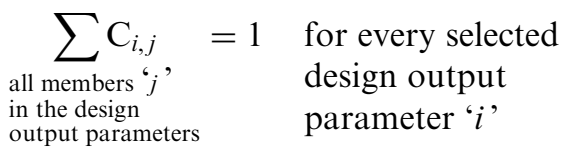

The functional links among feasible choice matrix element values and particular design input parameter values will be developed based on the developed input/ output interaction matrix, expert opinion, and the rules employed in the procedure.
Step 3. Generate feasible design alternatives

A matrix array is formed using the design output parameters and values. Each column in this array is a design output parameter vector corresponding to a particular pair of design output parameter values. To create a feasible design alternative, the design output parameter value array information is post-multiplied by a feasible choice matrix and a column vector with all elements equal to one, as shown below:

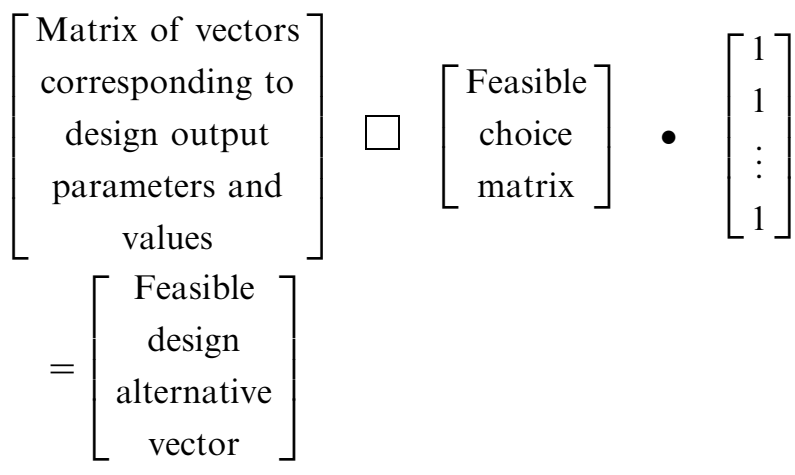

where $\square$ is the congruent matrix multiplication operator [24], • denote standard matrix multiplication, and a feasible design alternatives is represented by a vector of design output parameter values.

Figure 1 shows the overall development procedures for the matrix approach. Note that a particular customer's requirements, expressed in terms of a set of design input parameter values linked to several alternative choice matrices. Each distinct choice matrix can be used to

Figure 1. Conceptual framework for the matrix approach.

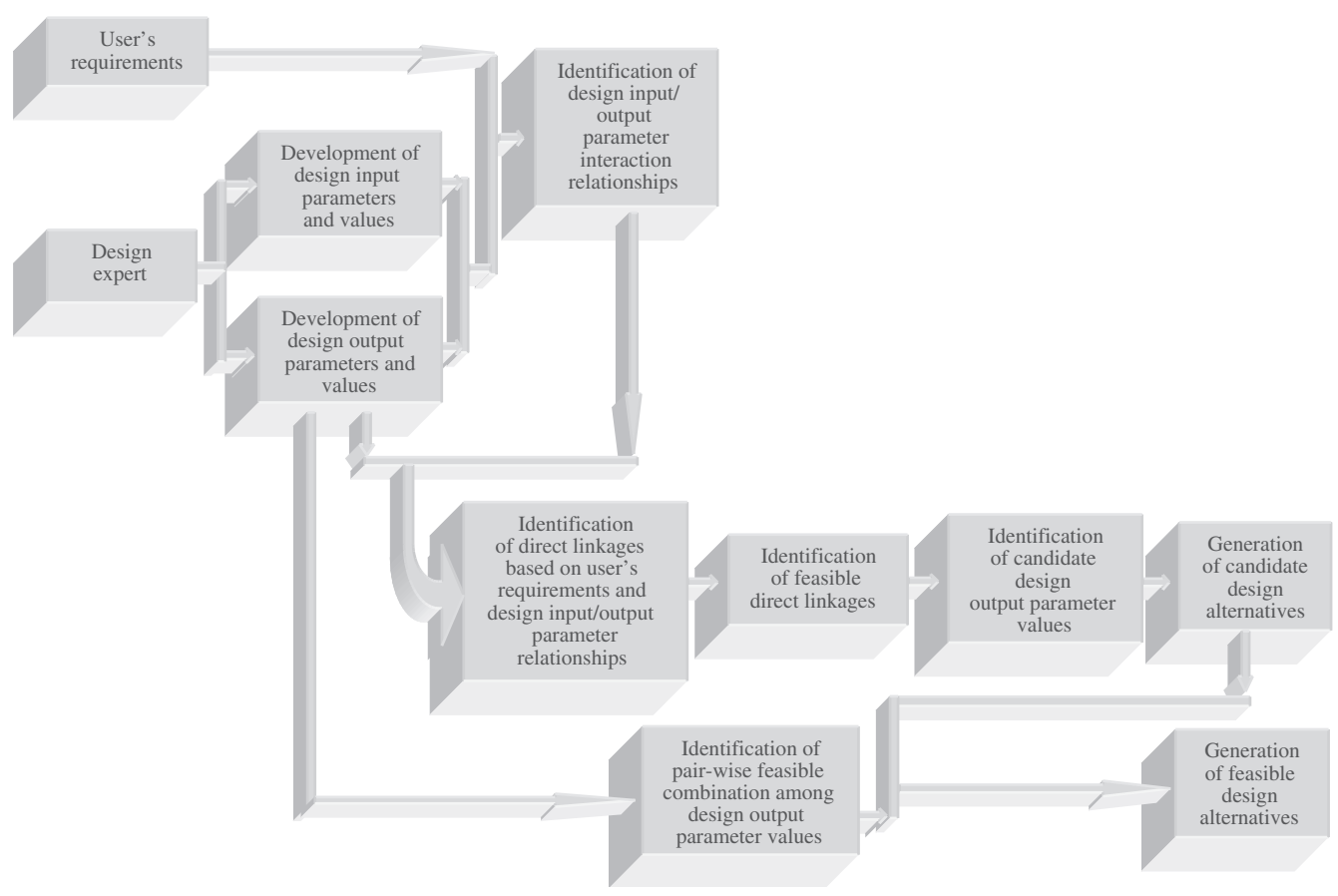


generate a feasible design alternative. Thus, the choice matrix plays a decisive role in design alternative creation. To generate an appropriate choice matrix, the designer must examine the relationships among the customer requirements, the input/output interaction matrix, and the design output parameter values matrix vectors.

\section{Development of the Matrix Approach}

Since customer input requirements and design output recommendations are two major parts in product design development, the component design strategy starts by defining design input parameters and values for the customer input requirements, and concludes with the design output parameter values for the design output recommendations. The design input parameters and values can include the customer's expected purchase price levels, operational functions, specific purchase objectives, and types of uses; while the design output parameters and values characterize the product components that are essential to the final product design.

Bridges such as performance data, facts, or rules are needed to link design input requirements with design output recommendations so that the designer can efficiently identify a suitable solution based on the specified customer requirements.

To explain how the matrix approach is developed, a sport shoe design will be used as an example to illustrate the steps of the proposed approach. The reason for choosing a sport shoe design as an example is that the sport shoe is a familiar product in almost everyone's daily life. Each year many new sport shoe styles come into the competitive market. The main components of a typical sport shoe are shown in Figure 2 [25].

\subsection{Identification of Input and Output Relationships}

Let $\mathrm{X}_{\mathrm{DIP}}$ denote the set of design input parameters that identify the labels or names. $Y_{D O P}$ denote the set of design output parameters that identify the labels or names.

$$
\begin{aligned}
\mathrm{X}_{\mathrm{DIP}} & =\left\{\mathrm{X}_{p} \mid p=1,2, \ldots, m\right\} \\
\mathrm{Y}_{\mathrm{DOP}} & =\left\{\mathrm{Y}_{i} \mid i=1,2, \ldots, n\right\}
\end{aligned}
$$

Meanwhile, let

$\mathrm{U}_{p}$ denote the set of $\mathrm{A}_{p}$ alternative design input parameter values corresponding to the design input parameter $\mathrm{X}_{p}, p=1,2, \ldots, m$.

$\mathrm{V}_{i}$ denote the set of $\mathrm{B}_{i}$ alternative design output parameter values corresponding to the design output parameter $\mathrm{Y}_{i}, i=1,2, \ldots, n$.

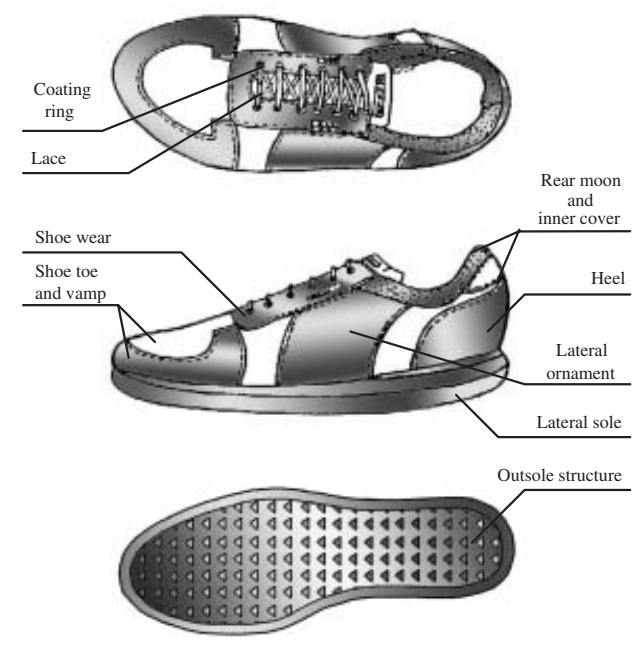

Figure 2. Characteristics of a sport shoe.

Thus, $\mathrm{U}_{p}=\left\{\mathrm{U}_{p, q_{p}} \mid q_{p}=1,2, \ldots, \mathrm{A}_{p}\right.$, and $p=1,2, \ldots$, $m\}$, and $\mathrm{V}_{i}=\left\{\mathrm{V}_{i, j_{i}} \mid j_{i}=1,2, \ldots, \mathrm{B}_{i}\right.$, and $\left.i=1,2, \ldots, n\right\}$.

Then, let

$\mathrm{X}$ denote the design input parameter concatenation identifiers $\mathrm{X}_{\mathrm{DIP}}$ and design input parameter values $\mathrm{U}_{p}$ to represent customer input requirements.

$\mathrm{Y}$ denote the design output parameter concatenation identifiers $Y_{D O P}$ and design output parameter values $\mathrm{V}_{i}$ to represent design output recommendations.

Hence, $\quad \mathrm{X}=\left\{\left(\mathrm{X}_{p}, \mathrm{U}_{p}\right) \mid p=1,2, \ldots, m\right\}, \quad$ and $\quad \mathrm{Y}=$ $\left\{\left(\mathrm{Y}_{i}, \mathrm{~V}_{i}\right) \mid i=1,2, \ldots, n\right\}$.

Tables 1 and 2 illustrate the representation of design input parameters and values $\mathrm{X}$, and design output parameters and values $\mathrm{Y}$, respectively, for the sport shoe design example [26-28].

Let I be a $\boldsymbol{n} \times \boldsymbol{m}$ interaction matrix with typical element $\mathrm{I}_{i, p}$, where

$$
\mathrm{I}_{i, p}= \begin{cases}1 & \begin{array}{l}
\text { if and only if } \mathrm{X}_{p} \text { has some } \\
\text { significant relationships } \\
\text { with } \mathrm{Y}_{i}, i=1,2, \ldots, n \\
\text { and } p=1,2, \ldots, m \\
\text { otherwise }
\end{array}\end{cases}
$$

The choice of the value ' 1 ' or ' 0 ' for each element of $\mathrm{I}_{i, p}$ is based on a judgment that the selection among the alternative design input parameter values $\mathrm{X}_{p}$ has a significant effect or a direct relationship on the appropriate selection of value(s) for the design output parameter $\mathrm{Y}_{i}$. Some of the considerations that are helpful in making this judgment include the price/cost of the product or product components, manufacturability of product components, functional characteristics of the product, and the properties of the product materials. 
Table 1. Design input parameters and values for the sport shoe design.

\begin{tabular}{|c|c|c|c|c|c|c|c|c|}
\hline \multirow{2}{*}{\multicolumn{2}{|c|}{$\begin{array}{l}\text { Design } \\
\text { input } \\
\text { parameter }\end{array}$}} & \multicolumn{7}{|c|}{ Design input parameter value } \\
\hline & & & 1 & 2 & 3 & 4 & 5 & 6 \\
\hline \multirow{6}{*}{\multicolumn{2}{|c|}{$\begin{array}{l}\text { TYPE OF USE } \\
\text { SHOE TYPE } \\
\text { COMFORT } \\
\text { SAFETY } \\
\text { COUNTER TYPE } \\
\text { ACCESSORY FUN }\end{array}$}} & \multirow{6}{*}{\multicolumn{2}{|c|}{$\begin{array}{l}\text { WALKING } \\
\text { WITH LACES } \\
\text { AIR CIRCULATION } \\
\text { DARKID } \\
\text { LOW } \\
\text { EQRMKEYNCOIN }\end{array}$}} & JOGGING & RUNNING & WORKING & SPORTING & NO PREFERENCE \\
\hline & & & & WITHOUT LACES & LACES W RINGS & LACES WT RINGS & NO PREFERENCE & \\
\hline & & & & SHOCKNVIBRED & MASSAGE EFFECT & NO PREFERENCE & & \\
\hline & & & & INJURYPRE & SLIDEPRE & NO PREFERENCE & & \\
\hline & & & & MEDIUM & $\mathrm{HIGH}$ & NO PREFERENCE & & \\
\hline & & & & EQIDCARD & CHGLATERALORNA & NO PREFERENCE & & \\
\hline \multicolumn{3}{|c|}{$\begin{array}{ll}\text { Note: } & \text { SHOCKNVIBRED } \\
& \text { DARKID } \\
& \text { INJURYPRE } \\
& \text { SLIDEPRE } \\
& \text { ACCESSORY FUN } \\
& \text { EQRMKEYNCOIN } \\
& \text { EQIDCARD } \\
& \text { CHGLATERALORNA }\end{array}$} & \multicolumn{2}{|c|}{$\begin{array}{l}\text { Shock and vibration reduction } \\
\text { Dark identification } \\
\text { Injury prevention } \\
\text { Slide prevention } \\
\text { Accessory function } \\
\text { Equip with room key and coins } \\
\text { Equip with ID cards } \\
\text { Changeable lateral ornament }\end{array}$} & & & & \\
\hline
\end{tabular}

\subsection{Identification of Feasible Direct Linkages}

In general, as a result of the interaction relationships specified by the input/output parameter interaction matrix, some values in $\mathrm{U}_{p, q_{p}}$ that relate to ergonomic considerations, product operation, proposed product uses, and customer characteristics will directly specify some set of values in $\mathrm{V}_{i, j_{i}}$.

Let $\mathrm{D}$ represent the set of direct linkages between design input parameter values and design output parameter values.

$\mathrm{D}=\left\{\left(\mathrm{U}_{p_{a}, q_{p a}}, \mathrm{~V}_{i_{a}, j_{i a}}\right) \mid p_{a} \in p, q_{p_{a}} \in \mathrm{A}_{p}, i_{a} \in i\right.$, and $\left.j_{i_{a}} \in \mathrm{B}_{i}\right\}$

Table 3 illustrates a portion of the set of direct linkages D (along with input and output parameter identifiers) among design input parameter values and design output parameter values for the sport shoe design example. A given set of customer requirements is represented by the vector UR, where $\mathrm{UR}=\left\{\mathrm{U}_{p_{b}, q_{p_{b}}} \mid p_{b} \in p ; q_{p_{b}} \in \mathrm{A}_{p}\right\}$. In this research, a set of specific customer requirements for the sport shoe design is chosen as follows:

$\begin{array}{ll}\text { Design input parameters } & \text { Design input parameter values } \\ \text { TYPE OF USE } & \text { JOGGING } \\ \text { SHOE TYPE } & \text { LACES W RINGS } \\ \text { COMFORT } & \text { AIR CIRCULATION } \\ \text { SAFETY } & \text { SLIDEPRE } \\ \text { COUNTER TYPE } & \text { NO PREFERENCE } \\ \text { ACCESSORY FUNCTN } & \text { EQIDCARD }\end{array}$

A matching procedure that considers the customer requirements can be employed to identify sets of direct links among the design input parameter values and design output parameter values that directly relate to a specific set of customer requirements. For each value $\mathrm{U}_{p_{b}, q_{p_{b}}}$ in UR that describes the customer requirement for related design input parameter $\mathrm{X}_{p_{b}}$, check to see if $\mathrm{D}$ specifies any relationship between the value $\mathrm{U}_{p_{b}, q_{p_{b}}}$ and some values $\mathrm{V}_{i_{a}, j_{i a}}$ for related design output parameter $\mathrm{Y}_{i_{a}}$. If $\mathrm{D}$ specifies a relationship between $\mathrm{U}_{p_{b}, q_{p_{b}}}$ and some $\mathrm{V}_{i_{a}, j_{i a}}$, then create an array entry for $\left[\mathrm{X}_{p_{b}}, \mathrm{U}_{p_{b}, q_{p_{b}}}\right.$, $\left.\mathrm{Y}_{i_{a}}, \mathrm{~V}_{i_{a}, j_{i_{a}}}\right]$ for each identified $\mathrm{V}_{i_{a}, j_{i a}}$. If the value $\mathrm{U}_{p_{b}, q_{p_{b}}}$ in UR is 'No Preference', which means that the customer does not specify a requirement for some particular design input parameter $X_{p_{b}}$, then there will be no values $\mathrm{V}_{i_{a}, j_{i a}}$ specified by this design input parameter value.

Let $\mathrm{D}_{\mathrm{IO}}$ denote the collection of all array entries for direct linkages based on a specific set of customer requirements and design input/output interaction relationships, then

$$
\begin{aligned}
\mathrm{D}_{\mathrm{IO}}= & \left\{\left(\mathrm{X}_{p_{b}}, \mathrm{U}_{p_{b}, q_{p_{b}}}, \mathrm{Y}_{i_{a}}, \mathrm{~V}_{i_{a}, j_{i_{a}}}\right) \mid\right. \\
& \left.p_{b} \in p, q_{p_{b}} \in q_{p}, i_{a} \in i, \text { and } j_{i_{a}} \in j_{i}\right\} .
\end{aligned}
$$

It is possible that different values $\mathrm{U}_{p_{b}, q_{p_{b}}}$ in UR link with different set of values $\mathrm{V}_{i_{a}, j_{i_{a}}}$ for the same design output parameter $\mathrm{Y}_{i_{a}}$. When this situation occurs, only those common values $\mathrm{V}_{i_{a}, j_{i_{a}}}$ for the design output parameter $\mathrm{Y}_{i_{a}}$ are considered as feasible. The reason for this classification is the requirement that values $\mathrm{V}_{i_{a}, i_{i_{a}}}$ specified by different customer requirements for the same design output parameter $\mathrm{Y}_{i_{a}}$ must simultaneously meet all of the given customer requirements. The intersection property from the theory of sets applies in this situation. Figure 3 illustrates that the design output parameter 'OUTSOLE STRUCT' is a feasible response to the set of design input parameter values 'JOGGING' and 'SLIDEPRE'. 
Table 2. Design output parameters and values for the sport shoe design.

\begin{tabular}{|c|c|c|c|c|c|c|c|c|c|c|}
\hline \multirow{2}{*}{$\begin{array}{l}\text { Design } \\
\text { output } \\
\text { parameters }\end{array}$} & \multicolumn{10}{|c|}{ Design output parameters value } \\
\hline & No.1 & No.2 & No.3 & No.4 & No.5 & No.6 & No.7 & No.8 & No.9 & No.10 \\
\hline \multicolumn{11}{|l|}{$\begin{array}{l}\text { Habit } \\
\text { feature }\end{array}$} \\
\hline $\begin{array}{l}\text { Conven- } \\
\text { ience } \\
\text { feature }\end{array}$ & $\begin{array}{l}\text { Small } \\
\text { pocket } \\
\text { sealed on } \\
\text { outer heel }\end{array}$ & $\begin{array}{l}\text { Small } \\
\text { pocket } \\
\text { separate } \\
\text { but can be } \\
\text { bound on } \\
\text { outer heel }\end{array}$ & $\begin{array}{l}\text { Small } \\
\text { pocket } \\
\text { separate } \\
\text { but can } \\
\text { be bound } \\
\text { on outer } \\
\text { lateral } \\
\text { ornament }\end{array}$ & $\begin{array}{l}\text { Small } \\
\text { pocket } \\
\text { sealed } \\
\text { on inner } \\
\text { lateral } \\
\text { ornament }\end{array}$ & $\begin{array}{l}\text { Small } \\
\text { pocket } \\
\text { sealed } \\
\text { on outer } \\
\text { lateral } \\
\text { ornament }\end{array}$ & $\begin{array}{l}\text { Small } \\
\text { pocket } \\
\text { sealed on } \\
\text { shoe wear }\end{array}$ & $\begin{array}{l}\text { Small pocket } \\
\text { separate } \\
\text { but can be } \\
\text { bound on } \\
\text { shoe wear }\end{array}$ & $\begin{array}{l}\text { Small } \\
\text { pocket } \\
\text { above } \\
\text { laces with } \\
\text { binding } \\
\text { band }\end{array}$ & $\begin{array}{l}\text { Small pocket } \\
\text { on both } \\
\text { outer heel } \\
\text { and outer } \\
\text { lateral } \\
\text { ornament }\end{array}$ & $\begin{array}{c}\text { Without } \\
\text { small } \\
\text { pocket }\end{array}$ \\
\hline $\begin{array}{l}\text { Safety } \\
\text { feature }\end{array}$ & $\begin{array}{l}\text { Fluorescent } \\
\text { on pocket } \\
\text { surface }\end{array}$ & $\begin{array}{l}\text { Fluorescent } \\
\text { on heel }\end{array}$ & $\begin{array}{l}\text { Fluorescent } \\
\text { on shoe toe }\end{array}$ & $\begin{array}{l}\text { Fluorescent } \mathrm{F} \\
\text { on outer } \\
\text { lateral } \\
\text { ornament }\end{array}$ & $\begin{array}{l}\text { Fluorescent } \\
\text { on both } \\
\text { heel and } \\
\text { shoe toe }\end{array}$ & $\begin{array}{l}\text { Fluorescent } \\
\text { on both } \\
\text { heel and } \\
\text { outer lateral } \\
\text { ornament }\end{array}$ & $\begin{array}{l}\text { Fluorescent } \\
\text { on both } \\
\text { shoe toe } \\
\text { and outer } \\
\text { lateral } \\
\text { ornament }\end{array}$ & $\begin{array}{l}\text { Fluorescent } \\
\text { on heel, } \\
\text { shoe toe } \\
\text { and outer } \\
\text { lateral } \\
\text { ornament }\end{array}$ & $\begin{array}{l}\text { Without } \\
\text { fluorescent } \\
\text { material }\end{array}$ & \\
\hline $\begin{array}{l}\text { Ventilation } \\
\text { feature }\end{array}$ & $\begin{array}{l}\text { Front } \\
\text { vamp with } \\
\text { small } \\
\text { holes }\end{array}$ & $\begin{array}{l}\text { Lateral } \\
\text { vamp } \\
\text { with } \\
\text { small } \\
\text { holes }\end{array}$ & $\begin{array}{l}\text { Front vamp } \\
\text { and lateral } \\
\text { vamp with } \\
\text { small holes }\end{array}$ & $\begin{array}{r}\text { Without } \\
\text { small } \\
\text { holes }\end{array}$ & & & & & & \\
\hline $\begin{array}{l}\text { Health } \\
\text { feature }\end{array}$ & $\begin{array}{l}\text { Massage } \\
\text { effect } \\
\text { using air } \\
\text { in midsole }\end{array}$ & $\begin{array}{l}\text { Massage } \\
\text { effect } \\
\text { using } \\
\text { wave type } \\
\text { of midsole }\end{array}$ & $\begin{array}{l}\text { Without } \\
\text { massage } \\
\text { effect }\end{array}$ & $\begin{array}{l}\text { Shock and } \\
\text { vibration } \\
\text { protection } \\
\text { effect on } \\
\text { midsole }\end{array}$ & $\begin{array}{l}\text { Shock and } \\
\text { vibration } \\
\text { protection } \\
\text { effect on } \\
\text { rear midsole }\end{array}$ & $\begin{array}{l}\text { Shock and } \\
\text { vibration } \\
\text { protection } \\
\text { on outsole }\end{array}$ & $\begin{array}{l}\text { Without shock } \\
\text { and vibration } \\
\text { effect }\end{array}$ & $\begin{array}{l}\text { Massage } \\
\text { and shock } \\
\text { and vibration } \\
\text { protection } \\
\text { effect }\end{array}$ & $\begin{array}{l}\text { No massage } \\
\text { shock and } \\
\text { vibration } \\
\text { protection } \\
\text { effect }\end{array}$ & \\
\hline \multicolumn{11}{|l|}{$\begin{array}{l}\text { Outsole } \\
\text { structure }\end{array}$} \\
\hline \multicolumn{11}{|l|}{$\begin{array}{l}\text { Rear moon } \\
\text { and inner } \\
\text { cover }\end{array}$} \\
\hline $\begin{array}{l}\text { Lateral } \\
\quad \text { ornament }\end{array}$ & & & & & None & & & & & \\
\hline Shoe wear & d & f & 1 & 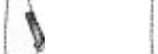 & & & & & ( & None \\
\hline \multicolumn{11}{|l|}{$\begin{array}{l}\text { Lateral } \\
\text { sole }\end{array}$} \\
\hline \multicolumn{11}{|c|}{$\begin{array}{l}\text { Shoe toe } \\
\text { and vamp }\end{array}$} \\
\hline Heel & & & & & & & None & & & \\
\hline
\end{tabular}


Table 3. A portion of direct linkages.

\begin{tabular}{|c|c|c|c|}
\hline DI parmeter & DIP value & DO parameter & DOP value \\
\hline TYPE OF USE & JOGGING & OUTSOLE STRUCT & NO.1 \\
\hline TYPE OF USE & JOGGING & OUTSOLE STRUCT & NO. 2 \\
\hline TYPE OF USE & JOGGING & OUTSOLE STRUCT & NO.3 \\
\hline TYPE OF USE & JOGGING & OUTSOLE STRUCT & NO.4 \\
\hline TYPE OF USE & JOGGING & OUTSOLE STRUCT & NO.6 \\
\hline TYPE OF USE & JOGGING & OUTSOLE STRUCT & NO.7 \\
\hline SHOE TYPE & LACES W RINGS & HABIT FEATURE & NO.1 \\
\hline COMFORT & AIR CIRCULATION & VENT FEATURE & NO.1 \\
\hline COMFORT & AIR CIRCULATION & VENT FEATURE & NO.2 \\
\hline COMFORT & AIR CIRCULATION & VENT FEATURE & NO.3 \\
\hline SAFETY & SLIDEPRE & OUTSOLE STRUCT & NO.5 \\
\hline SAFETY & SLIDEPRE & OUTSOLE STRUCT & NO. 6 \\
\hline SAFETY & SLIDEPRE & OUTSOLE STRUCT & NO.7 \\
\hline SAFETY & SLIDEPRE & OUTSOLE STRUCT & NO.8 \\
\hline SAFETY & SLIDEPRE & OUTSOLE STRUCT & NO.9 \\
\hline SAFETY & SLIDEPRE & OUTSOLE STRUCT & NO.10 \\
\hline COUNTER TYPE & $\mathrm{HIGH}$ & REAR MOIN COVER & NO.5 \\
\hline COUNTER TYPE & $\mathrm{HIGH}$ & REAR MOIN COVER & NO. 6 \\
\hline ACCESSORY FUNCTN & EQIDCARD & LATERAL ORNA & NO.1 \\
\hline ACCESSORY FUNCTN & EQIDCARD & LATERAL ORNA & NO.3 \\
\hline
\end{tabular}

Figure 3. Intersectional direct links based on two specific customer requirements.

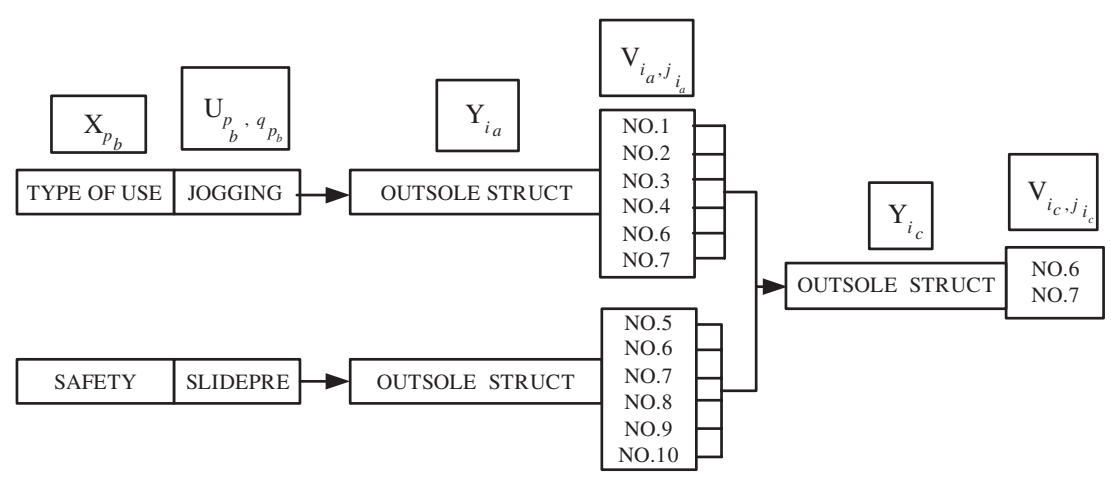

Let $\mathrm{Y}_{\mathrm{SH}}$ denote the collection of all array entries for shared design output parameters of intersectional direct links from $\mathrm{D}_{\mathrm{IO}}$, then $\mathrm{Y}_{\mathrm{SH}}=\left\{\mathrm{Y}_{i_{c}} \mid i_{c} \in i_{a}\right\}$.

Similarly, let $\mathrm{D}_{\mathrm{SH}}$ denote the collection of all array entries for shared direct links from $\mathrm{D}_{\mathrm{IO}}$, then

$$
\begin{aligned}
\mathrm{D}_{\mathrm{SH}}= & \left\{\left(\mathrm{X}_{p_{c}}, \mathrm{U}_{p_{c}, q_{p_{c}}}, \mathrm{Y}_{i_{c}}, \mathrm{~V}_{i_{c}, j_{i_{c}}}\right) \mid\right. \\
& \left.p_{c} \in p_{b}, q_{p_{c}} \in q_{p_{b}}, i_{c} \in i_{a}, \text { and } j_{i_{c}} \in j_{i_{a}}\right\} .
\end{aligned}
$$

Another situation occurs when different customer requirements do not share any common values of $\mathrm{V}_{i_{a}, j_{i a}}$ for the same design output parameter $\mathrm{Y}_{i_{a}}$. Here the customer must alter the set of customer requirements since there is no feasible design recommendation for this set of customer requirements.

A new array $\mathrm{D}_{\mathrm{IO}}^{\prime}$ will be formed from $\mathrm{D}_{\mathrm{IO}}$ to identify feasible direct links between design input parameter values and design output parameter values for a specific set of customer requirements and design input/output interaction relationships. That is, let $\mathrm{D}_{\mathrm{IO}}^{\prime}$ denote the collection of all array entries of feasible direct links from $\mathrm{D}_{\mathrm{IO}}$, then

$$
\begin{aligned}
\mathrm{D}_{\mathrm{IO}}^{\prime}= & \left\{\left(\mathrm{X}_{p_{b}^{\prime}}, \mathrm{U}_{p_{b}^{\prime}, q_{p_{b}^{\prime}}}, \mathrm{Y}_{i_{a}^{\prime}}, \mathrm{V}_{i_{a}^{\prime}, j_{i_{c}^{\prime}}}\right) \mid\right. \\
& \left.p_{b}^{\prime} \in p_{b}, q_{p_{b}^{\prime}} \in q_{p_{b}}, i_{c}^{\prime} \in i_{a}, \text { and } j_{i_{a}^{\prime}} \in j_{i_{a}}\right\} .
\end{aligned}
$$


To identify the feasible direct links from $\mathrm{D}_{\mathrm{IO}}$, a procedure must be developed that insures that different values $\mathrm{U}_{p_{b}, q_{p_{b}}}$ in $\mathrm{UR}$ are only linked with the shared values $\mathrm{V}_{i_{a}, j_{i a}}$ for each design output parameter $\mathrm{Y}_{i_{a}}$. The following two steps will be used to form $\mathrm{D}_{\mathrm{IO}}^{\prime}$.

Step 1. For each array entry in $\mathrm{D}_{\mathrm{IO}}$, check the values $\mathrm{U}_{p_{b}, q_{p}}$ associated with each design output parameter $\mathrm{Y}_{i_{a}}$. If there are different values $\mathrm{U}_{p_{b}, q_{p_{b}}}$ associated with same design output parameter $\mathrm{Y}_{i_{c}}$, then create an array entry $\left[\mathrm{Y}_{i_{c}}\right]$ in $\mathrm{Y}_{\mathrm{SH}}$ for the shared design output parameter $\mathrm{Y}_{i_{c}}$. If there are no such $\mathrm{Y}_{i_{c}}$, the intersection situation does not need to be considered. The purpose of creating the array $\left[\mathrm{Y}_{i_{c}}\right]$ in $\mathrm{Y}_{\mathrm{SH}}$ is to determine if the intersection situation occurs in $\mathrm{D}_{\mathrm{IO}}$; and, if it does occur, to determine which design output parameters are affected. Furthermore, if the different values $\mathrm{U}_{p_{b}, q_{p_{b}}}$ associated with each design output parameter $Y_{i_{c}}$ share some set of design output parameter values $\mathrm{V}_{i_{a}, j_{a} a}$, then create an entry in another array $\mathrm{D}_{\mathrm{SH}}$ for each $\left[\mathrm{X}_{p_{c}}, \mathrm{U}_{p_{c}, q_{p_{c}}}, \mathrm{Y}_{i_{c}}, \mathrm{~V}_{i_{c}, j_{i c}}\right]$ where the values $\mathrm{U}_{p_{c}, q_{p_{c}}}$ and $\mathrm{V}_{i_{c}, j_{i_{c}}}$ correspond to the shared relationship. The purpose of creating the array $\left[\mathrm{X}_{p_{c}}, \mathrm{U}_{p_{c}, q_{p_{c}}}, \mathrm{Y}_{i_{c}}, \mathrm{~V}_{i_{c}, j_{i_{c}}}\right]$ in $\mathrm{D}_{\mathrm{SH}}$ is to determine the common design output parameter values in $\mathrm{D}_{\mathrm{IO}}$ that are shared by different design input parameter values so that feasible direct links can be identified. Once the arrays $\left[\mathrm{Y}_{i_{c}}\right]$ in $\mathrm{Y}_{\mathrm{SH}}$ and $\left[\mathrm{X}_{p_{c}}, \mathrm{U}_{p_{c}, q_{p_{c}}}, \mathrm{Y}_{i_{c}}, \mathrm{~V}_{i_{c}, j_{i c}}\right]$ in $\mathrm{D}_{\mathrm{SH}}$ are formed, check to see if there is at least one $\left[\mathrm{X}_{p_{c}}, \mathrm{U}_{p_{c}, q_{p c}}, \mathrm{Y}_{i_{c}}, \mathrm{~V}_{i_{c}, j_{i c}}\right]$ in $\mathrm{D}_{\mathrm{SH}}$ for each entry $\left[\mathrm{Y}_{i_{c}}\right]$ in $\mathrm{Y}_{\mathrm{SH}}$. If so, then all of different values $\mathrm{U}_{p_{b}, q_{p_{b}}}$ associated with some design output parameter $\mathrm{Y}_{i_{a}}$ must share at least one common design output parameter values $\mathrm{V}_{i_{a}, j_{i a}}$ in $\mathrm{D}_{\mathrm{IO}}$. Step 2 in the determination of feasible direct links will actually create the array $\mathrm{D}_{\mathrm{IO}}^{\prime}$.

Step 2. From step 1, for each entry $\mathrm{Y}_{i_{c}}$ in $\mathrm{Y}_{\mathrm{SH}}$, place all of the identified entries $\left[\mathrm{X}_{p_{c}}, \mathrm{U}_{p_{c}, q_{p_{c}}}, \mathrm{Y}_{i_{c}}, \mathrm{~V}_{i_{c}, j_{i c}}\right]$ in the new array $\mathrm{D}_{\mathrm{IO}}^{\prime}$. For those $\mathrm{Y}_{i_{a}}$ in $\mathrm{D}_{\mathrm{IO}}$ that are not contained in the entries $\left[\mathrm{Y}_{i_{c}}\right]$ of $\mathrm{Y}_{\mathrm{SH}}$ place all of the corresponding $\left[\mathrm{X}_{p_{b}}, \mathrm{U}_{p_{b}, q_{p_{b}}}, \mathrm{Y}_{i_{a}}, \mathrm{~V}_{i_{a}, j_{i a}}\right]$ in $\mathrm{D}_{\mathrm{IO}}^{\prime}$.

\subsection{Candidate Design Output Parameter Value Identification}

The set of direct links $\mathrm{D}_{\mathrm{IO}}^{\prime}$, that relate a specific set of customer requirements and design input/output parameter interaction relationships to design output parameter values, can be used to determine the set of all candidate design alternative values.

A three-pronged procedure for candidate design output parameter value identification can be developed using these three decision criteria.

Compare each design output parameter $\mathrm{Y}_{i_{d}}$ corresponding to the row values $\mathrm{V}_{i_{d}, j_{i_{i}}^{k}}$ with the $\mathrm{Y}_{i_{a}^{\prime}}$ for array entries $\left[\mathrm{X}_{p_{b}^{\prime}}, \mathrm{U}_{p_{b}^{\prime}, q_{p_{b}^{\prime}}}, \mathrm{Y}_{i_{a}^{\prime}}, \mathrm{V}_{i_{a}^{\prime}, j_{a}^{\prime}}\right]$ in $\mathrm{D}_{\mathrm{IO}}^{\prime}$. (i) If there is no $Y_{i_{a}^{\prime}}$ that is equivalent to the design output parameter $\mathrm{Y}_{i_{d}}$, all of the row values $\mathrm{V}_{i_{d}, j_{i}^{k}}$ that correspond to design output parameter $\mathrm{Y}_{i_{d}}$ are available as candidate design output parameter values. Create a new array entry with $\left[\mathrm{V}_{i_{d}, j_{i}^{k}} \mid k=1,2, \ldots, \mathrm{B}_{i}\right]$.

(ii) If design output parameter $\mathrm{Y}_{i_{d}}$ matches some $\mathrm{Y}_{i_{a}^{\prime}}$ of array entries $\left[\mathrm{X}_{p_{b}^{\prime}}, \mathrm{U}_{p_{b}^{\prime}}, q_{p^{\prime}}, \mathrm{Y}_{i_{a}^{\prime}}, \mathrm{V}_{i_{a}^{\prime}}, j_{i^{\prime}}\right]$ in $\mathrm{D}_{\mathrm{IO}}^{\prime}$. Then check to see if any value $\mathrm{V}_{i_{d}, j_{i_{d}}^{k}}$ for that $\mathrm{Y}_{i_{d}}$ also matches $\mathrm{V}_{i_{a}^{\prime}, j_{i_{a}^{\prime}}}$ for the corresponding $\mathrm{Y}_{i_{a}^{\prime}}$.

(a) If only a portion of values $\mathrm{V}_{i_{d}, j_{i_{d}}^{k}}$, say $\mathrm{V}_{i_{d}, j_{i_{d}} k_{a}}$, matches some values $\mathrm{V}_{i_{a}^{\prime}, j_{i^{\prime}}}$ for the values $\mathrm{V}_{i_{d}, j_{i_{d}}^{k}}$ is available as candidate design output parameter values. Create a new array entry such that $\mathrm{V}_{i_{d}, j_{i^{\prime}} k_{a}}=\mathrm{V}_{i_{d}, j_{i d}^{k}}$, and $\mathrm{V}_{i_{d}, j_{i^{\prime}} k^{\prime}}={ }^{\prime * * *}$, where '***' means null value, $k_{a} \neq k_{b}$, and $k_{a} \cup k_{b}=k$.

(b) If none of the values $\mathrm{V}_{i_{d}, j_{i_{d}}^{k}}$ corresponding to design output parameter $\mathrm{Y}_{i_{d}}$ matches any value $\mathrm{V}_{i_{a}^{\prime}, j_{i^{\prime}}}$ corresponding to equivalent design output parameter $\mathrm{Y}_{i_{a}^{\prime}}$ in $\mathrm{D}_{\mathrm{IO}}^{\prime}$, then there are no candidate design alternative values for design output parameter $\mathrm{Y}_{i_{d}}$, and therefore no feasible design output parameter can be recommended.

Let CDPV denote the set of candidate design output parameter values that is identified from $\mathrm{V}_{i_{d}, j_{i^{\prime}}^{k}}$ for a specific set of customer requirements, with "typical element $\mathrm{CDPV}_{i_{d} k^{\prime}}$,

$$
\mathrm{CDPV}_{i_{d} k^{\prime}}= \begin{cases}\mathrm{V}_{i_{d}, j_{d}}^{k} & \text { if and only if } \mathrm{V}_{i_{d}, j_{i_{d}}^{k}}=\mathrm{V}_{i_{a}^{\prime}, j_{i}^{\prime}} ; \\ & j_{i_{d}}^{k} \in \mathrm{B}_{i}, i_{d}=1,2, \ldots, n, \\ & k=1,2, \ldots, \mathrm{B}_{i} ; \mathrm{V}_{i_{a}^{\prime}, j_{i}^{\prime}} \in \mathrm{D}_{\mathrm{IO}}^{\prime} \\ * * * & \text { otherwise }\end{cases}
$$

The collection of candidate design output parameter values CDPV that are identified from the design output parameter values using the set of customer requirements 'Jogging', 'Laces W Rings', 'Air Circulation', 'Slidepre', 'No Preference', and 'Equidcard' for the sport shoe design example is presented in Table 4.

\section{Generation of Feasible Design Alternatives}

The identified set of candidate design output values in CDPV that satisfy a specific set of customer requirements will be used to generate feasible design alternatives. Since a design alternative is generated by selecting a candidate design output parameter value for each corresponding design output parameter, the set of candidate design output parameter values in CDPV can be used to generate many different design alternatives. However, some design output parameter value combinations may need to be avoided to insure that feasible design alternatives are generated. 
Table 4. A collection of candidate design output parameter values for a specific set of customer requirements.

\begin{tabular}{|c|c|c|c|c|c|c|c|c|c|c|}
\hline \multirow{2}{*}{$\begin{array}{l}\text { Design } \\
\text { output } \\
\text { parameter } \\
\text { Habit feature }\end{array}$} & \multicolumn{10}{|c|}{ Candidate design output parameter value CDPV } \\
\hline & No.1 & $* * *$ & $* * *$ & $* * *$ & $* * *$ & $* * *$ & $* * *$ & $* * *$ & $* * *$ & $* * *$ \\
\hline Convenience feature & No.1 & No.2 & No.3 & No.4 & No.5 & No.6 & No.7 & No.8 & No.9 & No.10 \\
\hline Safety feature & No.1 & No.2 & No.3 & No.4 & No.5 & No.6 & No.7 & No.8 & No.9 & $* * *$ \\
\hline Vent feature & No.1 & No.2 & No.3 & $* * *$ & $* * *$ & $* * *$ & $* * *$ & $* * *$ & $* * *$ & $* * *$ \\
\hline Health feature & No.1 & No.2 & No.3 & $* * *$ & $* * *$ & $* * *$ & $* * *$ & $* * *$ & $* * *$ & $* * *$ \\
\hline Outsole struct & $* * *$ & $* * *$ & $* * *$ & $* * *$ & $* * *$ & No.6 & No.7 & $* * *$ & $* * *$ & $* * *$ \\
\hline Rear moin cover & $* * *$ & $* * *$ & $* * *$ & $* * *$ & No.5 & No.6 & $* * *$ & $* * *$ & $* * *$ & $* * *$ \\
\hline Lateral orna & No.1 & $* * *$ & No.3 & $* * *$ & $* * *$ & $* * *$ & $* * *$ & $* * *$ & $* * *$ & $* * *$ \\
\hline Shoe wear & No.1 & No.2 & No.3 & No.4 & No.5 & No.6 & No.7 & No.8 & No.9 & None \\
\hline Lateral sole & No.1 & No.2 & No.3 & $* * *$ & $* * *$ & No.6 & No.7 & $* * *$ & $* * *$ & $* * *$ \\
\hline Shoe toe-vamp & No.1 & No.2 & No.3 & No.4 & No.5 & No.6 & No.7 & $* * *$ & $* * *$ & $* * *$ \\
\hline Heel & No.1 & No.2 & No.3 & No.4 & No.5 & No.6 & None & $* * *$ & $* * *$ & $* * *$ \\
\hline
\end{tabular}

\subsection{Pair-wise Feasible Combination Identification}

In general, there are three rules that can be used to help identify feasible output parameter value choices in generating a candidate design output parameter value.

Rule 1. The choice of a candidate design output

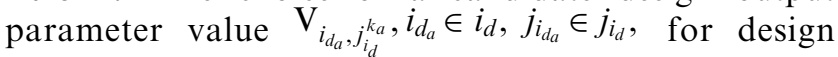
output parameter $\mathrm{Y}_{i_{d_{d}}}$ requires the selection of one value from an identified subset of the values for some other design output parameter, say $\mathbf{Y}_{i_{d_{b}}}$. This identified subset is a subset of the design output parameter values associated with $\mathrm{Y}_{i_{d_{h}}}$ in which there is at least one design output parameter value. Rule 1 is based on two considerations. (1) If a particular value should be chosen for some design output parameter, then try to use the same value for related design output parameters to reduce cost and increase efficiency for inventory control. (2) As a consequence of the limitations associated with current manufacturing techniques, if a particular value is chosen for some design output parameter, the choice of values that can be used for another design output parameter may be limited.

Let FC denote the set of all feasible pair-wise combinations among design output parameter values, then

$$
\mathrm{FC}=\left\{\left(\mathrm{V}_{i_{e}, j_{i_{e}}}, \mathrm{~V}_{i_{f}, j_{i_{f}}}\right) \mid i_{e}, i_{f} \in \mathrm{B}_{i} ; i_{e}, i_{f} \in n\right\},
$$

where $\mathrm{V}_{i_{e}, j_{i e}}$ represents a choice of values for design output parameter $\mathrm{Y}_{i_{e}}$, and $\mathrm{V}_{i_{f}, j_{i f}}$ represents a selection of values for some other design output parameter $\mathrm{Y}_{i_{f}}$ so that each pair of values $\left(\mathrm{V}_{i_{e}, j_{i_{e}}}, \mathrm{~V}_{i_{f}, j_{i_{f}}}\right)$ is pair-wise feasible.

To help identify all possible feasible combinations for FC, two special cases of Rule 1 are also described in Rule 2 and Rule 3.
Rule 2. The candidate design output parameter value choice $\mathrm{V}_{i_{d_{a}}, j_{d a}^{k}}, i_{d_{a}} \in i_{d}, j_{i_{d a}} \in j_{i_{d}}$ (could be the value 'NONE'), for design output parameter $\mathrm{Y}_{i_{d q}}$ requires the choice of the value 'NONE' for some other design output parameter, say $\mathrm{Y}_{i_{d_{b}}}$.

Rule 3. The candidate design output parameter value choice $\mathrm{V}_{i_{d_{d}}, j_{i_{d}}^{k}}, i_{d_{a}} \in i_{d, j_{i_{d}}} \in j_{i_{d}}$, for the design output parameter $\mathrm{Y}_{i_{d a}}$ requires choosing value $\mathrm{V}_{i_{d_{b}}, j_{i_{b}}^{k}}, i_{d_{b}} \in$ $i_{d, j_{d_{b}}} \in j_{i_{d}}$, for some other design output parameter, say $\mathrm{Y}_{i_{d_{b}}}$, and vice versa. Rule 3 implies that if two or more permissible values for two or more different design output parameters are simultaneously linked, then a specification must be made for the design output parameter values for all of the linked design output parameters at the same time.

Based on the three rules defined above, it is possible to identify a set of design output parameter values that constrain the choice of values for other design output parameters in generating feasible design alternatives.

\subsection{Procedures for Feasible Design Alternatives Generation}

Once candidate design output parameter values CDPV and feasible combinations among the design output parameter values FC are identified, a procedure can be employed to generate feasible design alternatives.

Let CDA denote an $\boldsymbol{n}$-dimensional column vector describing a candidate design alternative, with typical element $\mathrm{CDA}_{i_{d}}$, specifying a value for the design output parameter $\mathrm{Y}_{i_{d}}$, where $\mathrm{CDA}_{i_{d}}=\mathrm{V}_{i_{d}, j_{i}^{k}}$, if and only if a value $\mathrm{V}_{i_{d}, j_{i_{d}}^{k}}$ in CDPV is chosen; $i_{d}=1,2, \ldots, n$, and $k=1,2, \ldots, \mathrm{B}_{i}$. 
Similarly, let FDA denote an $\boldsymbol{n}$-dimensional column vector describing a feasible design alternative, with typical element $\mathrm{FDA}_{i_{d_{c}}}$ specifying a value for the design output parameter $\mathrm{Y}_{i_{d_{c}}}$, where $\mathrm{FDA}_{i_{d_{c}}}=\mathrm{V}_{i_{d_{c}}, j_{i_{c}}^{k}}$, if any value $\mathrm{V}_{i_{d}, j_{i_{d}}^{k}}$ in CDA is pair-wise feasible or can be modified to be pair-wise feasible; $i_{d_{c}}=1,2, \ldots, n$, and $k=1,2, \ldots, \mathrm{B}_{i}$.

To form FDA, a four-step procedure is developed with choices for a candidate design output parameter value from the first row of CDPV values serving as a starting point. Several alternative procedures could be used to generate candidate design alternatives (CDAs) from use of the back and forth route in the procedure for the generation of candidate design alternatives as shown in Figure 4.

Step 1. A candidate design output parameter value $\mathrm{V}_{i_{d}, j_{i}^{k}}$ from CDPV is selected as a row entry for a candidate design alternative CDA. In the first pass through Step 1, arbitrarily select a candidate design output parameter value (a value other than '***') from the first CDPV row. In subsequent passes through Step 1, identify an entry in CDA that as yet has no assigned design output parameter value. If all entries in CDA have been assigned a design output parameter value, go to Step 4. If an unassigned CDA entry has been identified, arbitrarily choose a parameter value (other than '***') from the corresponding row of candidate design output parameter values in CDPV, say $\mathrm{V}_{i_{d_{d}}, j_{i_{d}}^{k_{c}}}$ $i_{d_{a}} \in i_{d, j_{i_{a}}} \in j_{i_{d}}$, and $k_{c} \in \mathrm{B}_{i}$. In each pass through Step 1 , place the chosen value $\mathrm{V}_{i_{d a}}, j_{i_{d}}^{k_{c}}$ in the corresponding entry of FDA as the design output parameter value.

Step 2. The procedure identifies values $\mathrm{V}_{i_{f}, j_{i_{f}}}$ from the set of feasible combinations FC that can be selected in conjunction with the value $\mathrm{V}_{i_{d_{d}}, j_{i_{d}} k_{c}}$ identified in the last pass through Step 1. Let $\mathrm{FC}_{\mathrm{ST}}$ denote the collection of all array entries for pair-wise feasible design output parameter values $\mathrm{V}_{i_{f}, j_{i}}$ with corresponding design output parameters $\mathrm{Y}_{i_{f}}$ that are identified from $\mathrm{FC}$ in conjunction with the chosen candidate design output parameter value $\mathrm{V}_{i_{d_{a}}, j_{i_{d}}}$ from CDPV, then $\mathrm{FC}_{\mathrm{ST}}=$ $\left\{\left(\mathrm{Y}_{i_{f}}, \mathrm{~V}_{i_{f}, j_{i_{f}}}\right) \mid i_{f} \in i\right.$, and $\left.j_{i_{f}} \in j_{i}\right\}$. For the value $\mathrm{V}_{i_{d_{d}}, j_{i_{c}}}$ selected in Step 1, check the set of feasible combinations FC to see if the value $\mathrm{V}_{i_{d_{d}}, j_{i_{d}} k_{c}}$ matches any value $\mathrm{V}_{i_{e}, j_{i}}$ in the array entries $\left[\mathrm{V}_{i_{e}, j_{i e}}, \mathrm{~V}_{i_{f}, j_{i f}}\right]$ of FC. If the value $\mathrm{V}_{i_{d a}, j_{i_{c}}}$ does not match any value $\mathrm{V}_{i_{e}, j_{i}}$, then the procedure returns to Step 1 to select another candidate design output parameter value, say $\mathrm{V}_{i_{d_{b}}, j_{i_{d}}^{k}}, i_{d_{b}} \in i_{d}, j_{i_{d_{b}}} \in j_{i_{d}}, k_{c} \in k$, from CDPV for the next unassigned entry in the candidate design alternative CDA. If the value $\mathrm{V}_{i_{d_{d}}, j_{i_{d}}}$ matches any value $\mathrm{V}_{i_{e}, j_{i e}}$ in the array entries $\left[\mathrm{V}_{i_{e}, j_{e}}, \mathrm{~V}_{i_{f}, j_{i_{f}}}\right]$ of FC, then the choice of the value $\mathrm{V}_{i_{d_{d}}, j_{i_{d}}^{k_{c}}}$ for the corresponding design output parameter $\mathrm{Y}_{i_{d_{a}}}$ of CDA requires the selection of one of the values $\mathrm{V}_{i_{f}, j_{i_{f}}}$ from the array entries $\left[\mathrm{V}_{i_{e}, j_{i e}}, \mathrm{~V}_{i_{f}, j_{i}}\right]$ of $\mathrm{FC}$ to create a candidate design alternative. Create a new array entry $\left[\mathrm{Y}_{i_{f}}, \mathrm{~V}_{\left.i_{f}, j_{i_{f}}\right]}\right.$ in $\mathrm{FC}_{\mathrm{ST}}$ for each identified feasible combination as shown in Table 5.

Step 3. The procedure selects design output parameter

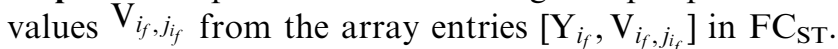
For each different design output parameter $Y_{i_{f}}$ in the array entries $\left[\mathrm{Y}_{i_{f}}, \mathrm{~V}_{i_{f}, j_{i_{f}}}\right]$ in $\mathrm{FC}_{\mathrm{ST}}$, check to see if any of the related values $\mathrm{V}_{i_{f}, j_{i_{f}}}$ appears in the corresponding row of candidate design output parameter values

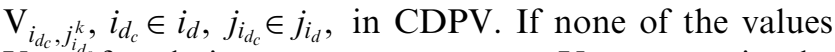
$\mathrm{V}_{i_{f}, i_{i f}}$ for design output parameter $\mathrm{Y}_{i_{f}}$ appear in the related row of CDPV, then the search for a feasible value for design output parameter $\mathrm{Y}_{i_{d_{c}}}$ has failed. The design output parameter value $\mathrm{V}_{i_{d_{d}}, j_{i_{d}} k_{d_{c}}}$ that was selected for the $\mathrm{Y}_{i_{d_{a}}}$ position in CDA in the last pass through Step 1 is removed, and the procedure returns to Step 1 to make a new design output parameter value selection for $\mathrm{Y}_{i_{d_{a}}}$. If at least one value $\mathrm{V}_{i_{f}, j_{i f}}$ for each different design output parameter $\mathrm{Y}_{i_{f}}$ appears in the related rows of candidate design output parameter values $\mathrm{V}_{i_{d_{c}}, j_{i_{d_{c}}}^{k}}$ in CDPV, then arbitrarily choose a value, say $\mathrm{V}_{i_{d_{c}}, j_{i_{d_{c}}}^{k} \text {, }}$ $k_{d} \in k$, where $\mathrm{V}_{i_{d_{c}}, j_{i_{d}}}=\mathrm{V}_{i_{f}, j_{i_{a}}}, j_{i_{f_{a}}} \in j_{i_{f}}$, from CDPV for each $Y_{i_{f}}$. There are three alternative situations that may

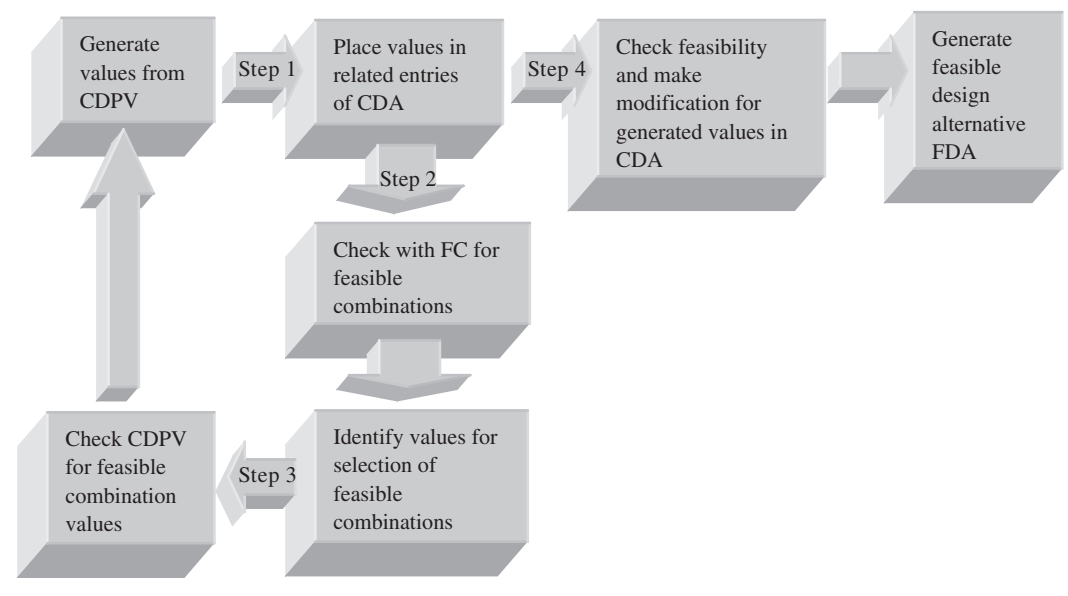

Figure 4. Framework for the generation of a feasible design alternative. 
Table 5. Identification of feasible combinations.

\begin{tabular}{|c|c|c|c|}
\hline \multicolumn{2}{|c|}{ Choice of design output parameter value } & \multicolumn{2}{|c|}{ Feasible pair of design output parameter value } \\
\hline $\begin{array}{l}\text { Design output } \\
\text { parameter } Y_{i_{e}}\end{array}$ & $\begin{array}{c}\text { Design output } \\
\text { parameter value } \mathbf{V}_{i_{\mathrm{e}}, j_{\mathrm{e}}}\end{array}$ & $\begin{array}{l}\text { Design output } \\
\text { parameter } Y_{i_{f}}\end{array}$ & $\begin{array}{c}\text { Design output } \\
\text { parameter value } V_{i_{f}, j_{f}}\end{array}$ \\
\hline HABIT FEATURE & NO.3 & SHOE WEAR & NONE \\
\hline CONVENIENCE FEA & NO.6 & WHOE WEAR & NO.6 \\
\hline CONVENIENCE FEA & NO.6 & SHOE WEAR & NO.7 \\
\hline CONVENIENCE FEA & NO.6 & SHOE WEAR & NO.8 \\
\hline CONVENIENCE FEA & NO.9 & HEEL & NO.1 \\
\hline CONVENIENCE FEA & NO.9 & HEEL & NO.2 \\
\hline CONVENIENCE FEA & NO.9 & HEEL & NO.3 \\
\hline CONVENIENCE FEA & NO.9 & HEEL & NO.4 \\
\hline CONVENIENCE FEA & NO.9 & HEEL & NO.5 \\
\hline$\ldots$ & $\ldots$ & $\ldots$ & $\ldots$ \\
\hline LATERAL ORNA & NO.4 & SHOE WEAR & NO.1 \\
\hline LATERAL ORNA & NO.4 & SHOE WEAR & NO.2 \\
\hline LATERAL ORNA & NO.4 & SHOE WEAR & NO.3 \\
\hline LATERAL ORNA & NO.4 & SHOE WEAR & NO.4 \\
\hline LATERAL ORNA & NO.4 & SHOE WEAR & NO.5 \\
\hline LATERAL ORNA & NO.4 & SHOE WEAR & NO.9 \\
\hline$\cdots$ & $\ldots$ & $\ldots$ & $\ldots$ \\
\hline
\end{tabular}

occur for each selected candidate design output parameter value $\mathrm{V}_{i_{d_{c}}, j_{i_{d}}}$.

1. If the corresponding entry in CDA as yet has no assigned design output parameter value, then place the value $\mathrm{V}_{i_{d_{c}}, j_{i_{d}}}$ in that entry of CDA.

2. If the corresponding entry in CDA has been assigned a design output parameter value from a previous step of the procedure and the assigned value equals $\mathrm{V}_{i_{d_{c}}, j_{i_{d}}, k_{d}}$, then return to Step 1 for the next assignment to CDA.

3. If the corresponding entry in CDA has been assigned a design output parameter value from a previous step of procedure and the assigned value differs

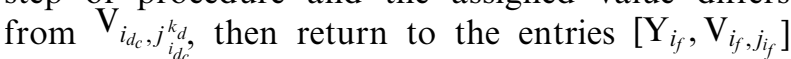
in $\mathrm{FC}_{\mathrm{ST}}$. Check to see if there is any other value $\mathrm{V}_{i_{f}, j_{i_{f}}}$ in the entries $\left[\mathrm{Y}_{i_{f}}, \mathrm{~V}_{i_{f}, j_{i_{f}}}\right]$ of $\mathrm{FC}_{\mathrm{ST}}$ that equals the assigned value. If there is another value, say

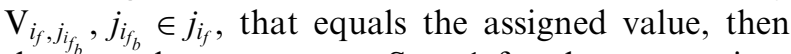
the procedure returns to Step 1 for the next assignment to CDA. Otherwise, the design output parameter value $\mathrm{V}_{i_{d_{\alpha}}, i_{i c}}$ that was selected for the $\mathrm{Y}_{i_{d_{a}}}$ position in $\mathrm{CDA}^{\text {in }}$ in the last pass through Step 1 is removed and the procedure returns to Step 1 to make a new design output parameter value selection for $\mathrm{Y}_{i_{d_{a}}}$.

The procedure moves back and forth through Step 1, Step 2, and Step 3 until all of the entries in the CDA are filled with design output parameter values. A feasibility checking procedure is employed in Step 4 of the procedure to expand upon the pair-wise determination of feasible choices used in FDA generation. If necessary, Step 4 modifies the CDA elements to insure that the set of design output parameter values constitute a feasible design alternative FDA.

Step 4. The procedure checks feasibility and makes possible modifications to design output parameter values. Each pair of the $\mathrm{FC}$ array $\left[\mathrm{V}_{i_{e}, j_{i e}}, \mathrm{~V}_{i_{f}, j_{i_{f}}}\right]$ is used in conjunction with the design output parameter values in CDA to determine if a feasible value $\mathrm{V}_{i_{f}, j_{i_{f}}}$ is specified in CDA for each $\mathrm{V}_{i_{e}, j_{i e}}$ in CDA.

Let MDF denote a $\boldsymbol{n}$-dimensional column vector describing the status of the feasibility checking and modification process for the entries of CDA that were generated from Step 1 to Step 3 of the procedure, with typical element $\mathrm{MDF}_{i_{d_{c}}}$,

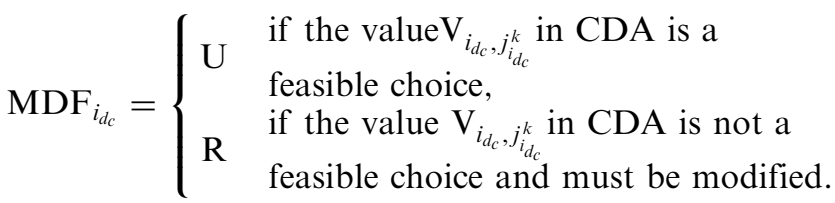

Basically, there are four situations that may occur in the feasibility checking procedure for a design alternative that was previously generated in Step 1, Step 2, and Step 3.

1. If a value $\mathrm{V}_{i_{d_{c}}, j_{i_{d_{c}}}^{k}}$ in CDA does not match any of the $\mathrm{V}_{i_{e}, j_{i_{e}}}$ in the array entries $\left[\mathrm{V}_{i_{e}, j_{i}}, \mathrm{~V}_{i_{f}, j_{i_{f}}}\right]$, then place the 
array entry $[\mathrm{U}]$ in MDF in the position corresponding to value $\mathrm{V}_{i_{d_{c}}, j_{i_{d_{c}}}^{k}}$ in CDA.

2. If a value $\mathrm{V}_{i_{d_{c}}, j_{i_{d c}}^{k}}$ in CDA matches a value $\mathrm{V}_{i_{e}, j_{i e}}$ in the array entries $\left[\mathrm{V}_{i_{e}, j_{i}}, \mathrm{~V}_{i_{f}, j_{i_{f}}}\right]$ and a pair-wise feasible value $\mathrm{V}_{i_{f}, i_{i_{f}}}$ is also specified in CDA, then create two array entries $[\mathrm{U}]$ in MDF in the positions corresponding to values $\mathrm{V}_{i_{d_{c}}, j_{i}}$ and $\mathrm{V}_{i_{f}, j_{i f}}$ in CDA.

3. If any value $\mathrm{V}_{i_{d_{c}}, j_{i_{d}}^{k}}$ in CDA matches a value $\mathrm{V}_{i_{e}, j_{i e}}$ in the array entries $\left[\mathrm{V}_{i_{e}, j_{i e}}, \mathrm{~V}_{i_{f}, j_{i_{f}}}\right]$ with some values $\mathrm{V}_{i_{f}, j_{i_{f}}}$ specified to be pair-wise feasible, but the value, say $\mathrm{V}_{i_{d_{e}}, j_{i_{d}}}, i_{d_{e}} \in i_{d}, j_{i_{d_{e}}} \in j_{i_{d}}, k_{e} \in k$, in the related CDA entry is not pair-wise feasible with the value $\mathrm{V}_{i_{d_{c}}, j_{d_{d}}^{k}}$, then an infeasible element has been identified. When this situation occurs, select a value, say $\mathrm{V}_{i_{f}, j_{i_{f}}}, j_{i_{f_{d}}} \in j_{i_{f}}$, from the specified values $\mathrm{V}_{i_{f}, j_{i_{f}}}$ that appear in the related CDPV row, say $\mathrm{V}_{i_{d_{e}}, j_{i f}}, k_{f} \in k$, to replace $\mathrm{V}_{i_{d_{e}}, j_{i_{d}}}$ in CDA. Create an array entry [U] in MDF in the position corresponding to value $\mathrm{V}_{i_{d_{c}}, j_{d_{c}}^{k}}$ in CDA and an array entry [R] in MDF in the position corresponding to the new feasible value $\mathrm{V}_{i_{d_{e}}, j_{i}} k_{f}$ in CDA.

4. In situation 3 , if none of the values $\mathrm{V}_{i_{f}, i_{i_{f}}}$ specified to be pair-wise feasible in conjunction with the value $\mathrm{V}_{i_{d_{c}}, j_{i}^{k}}$ appear in the related CDPV row, then the procédure returns to Step 1 for the generation of a new feasible design alternative.

Based on the four situations, the feasibility checking procedure examines each CDA entry to determine if any modification is required. An array entry [U] or [R] that corresponds to the CDA entry under examination is then created for MDF. As the CDA entries are examined, the MDF array is also formed. Once an entry has been selected for every MDF element, all of the MDF elements are examined. If all the MDF array entries are filled with [U], then place all the values $\mathrm{V}_{i_{d_{c}}, j_{i_{d}}^{k}}$ of CDA in the corresponding entries of a new array FDA. Thus, the feasibility checking procedure of Step 4 is completed, and the procedure has generated a feasible design alternative. If at least one array entry [R] appears in MDF, then the feasibility checking procedure in Step 4 reexamines each CDA entry to determine if any modification is required, and makes the necessary changes in the array entries for the generated MDF. An array entry $[\mathrm{U}]$ in MDF will be replaced by an array entry [R] if the value $\mathrm{V}_{i_{d_{c}}, j_{i_{c}}^{k}}$ in CDA was feasible in the last pass through Step 4 of the feasibility checking procedure but is found to be not feasible on this reexamination and must be modified. An $[R]$ array entry in the MDF will be replaced by a [U] array entry if the value $\mathrm{V}_{i_{d_{c}}, j_{i_{d_{c}}}^{k}}$ in the CDA was modified in the last pass through Step 4 but is found to be feasible on this reexamination. Again, once all the elements of CDA have been examined, the array MDF has been reformed. The procedure continues until all the array entries in MDF are filled with $[\mathrm{U}]$ and a feasible design alternative
FDA is generated. However, if in the process of revising MDF a previously assigned entry [R] in MDF is replaced by a second $[R]$ entry (implying two changes of the same design output parameter value in an attempt to secure feasibility), the procedure returns to Step 1 for the generation of a new candidate design alternative CDA. Figure 5 illustrates how a candidate design alternative is generated and modified into a feasible design alternative using Step 4 of the procedure. The matrix approach incorporating the congruent matrix multiplication in the generation of a feasible design alternative for the sport shoe design is shown in Figure 6.

\subsection{Development of the Uniquely Checking Procedure}

It is possible that in generating a set of feasible design alternatives for a specific set of customer requirements, the procedure will generate more than one copy of one or more design alternatives. A checking procedure can be used to insure that each feasible design alternative is unique.

Let UNIFDA denote a set of $N$ unique feasible design alternatives, with typical column array $\mathrm{UNIFDA}_{I}$ representing feasible design alternative $I, \mathrm{UNIFDA}=\left\{\mathrm{FDA}_{I} \mid\right.$ $I=1,2, \ldots, N\}$.

The checking procedure begins by placing all generated values of the first feasible design alternative in the corresponding row entries of the first UNIFDA column. Whenever a new feasible design alternative is generated, all of the design output parameter values are compared with the corresponding row values for each feasible design alternative in UNIFDA. If the comparison shows that the new feasible design alternative is different from any feasible design alternative in UNIFDA, then the new feasible design alternative is added as a new column in UNIFDA; otherwise, the new design alternative is discarded even though it is feasible, and the alternative generation procedure continues until a specified number of unique feasible design alternatives is identified.

\section{Conclusions}

Customer-oriented product design in CE is critically important to manufacturing but heavily relies on the designer's experience and ideas. When the product designer or design team develops a product design using classical methods, the range of alternatives that are developed is limited by the creativity of the designer or team members. In general, the most important factor influencing the quality and efficiency of product design is the availability of modeling tools and design methods for the designers. Unfortunately, current product design methods emphasize the analysis phase of design solutions rather than the synthesis phase of generating 
Figure 5. Routes for the generation of feasible design alternatives.
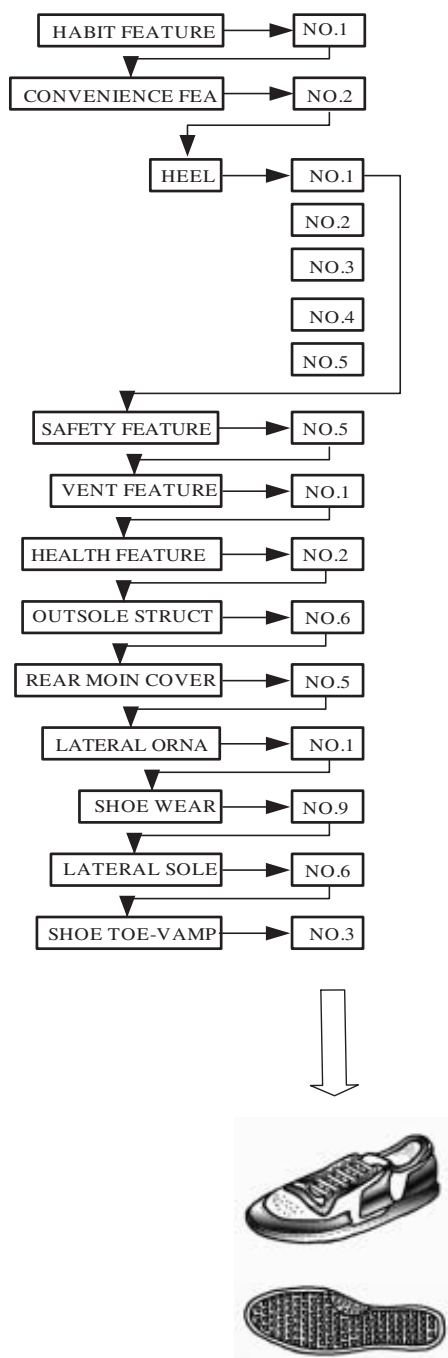

FDA 1

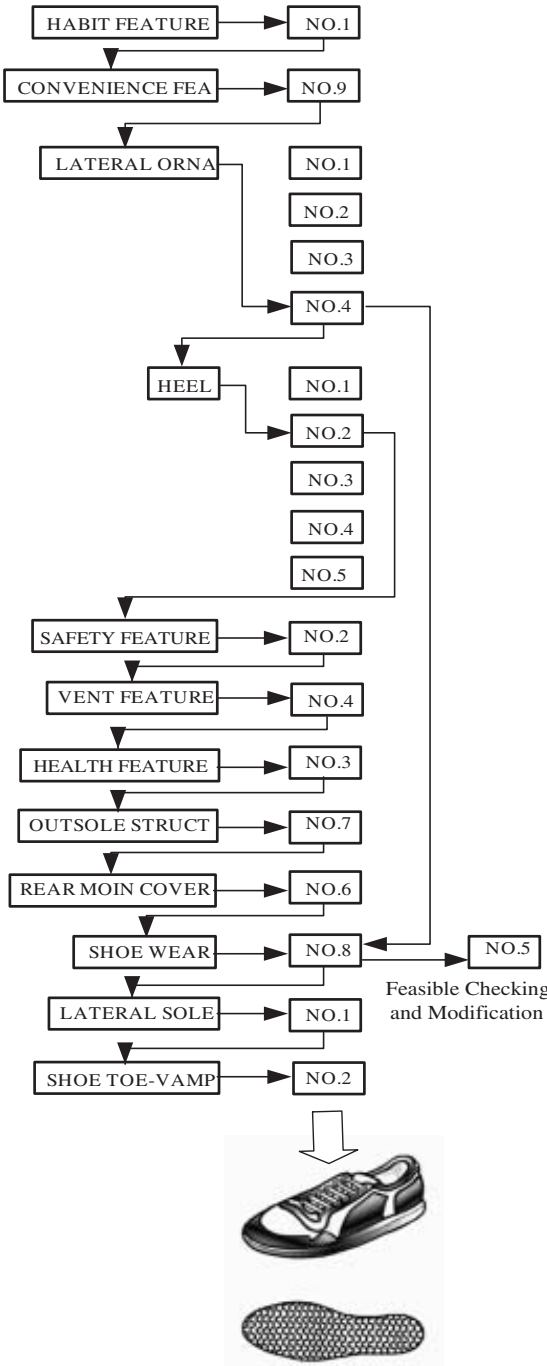

FDA 2

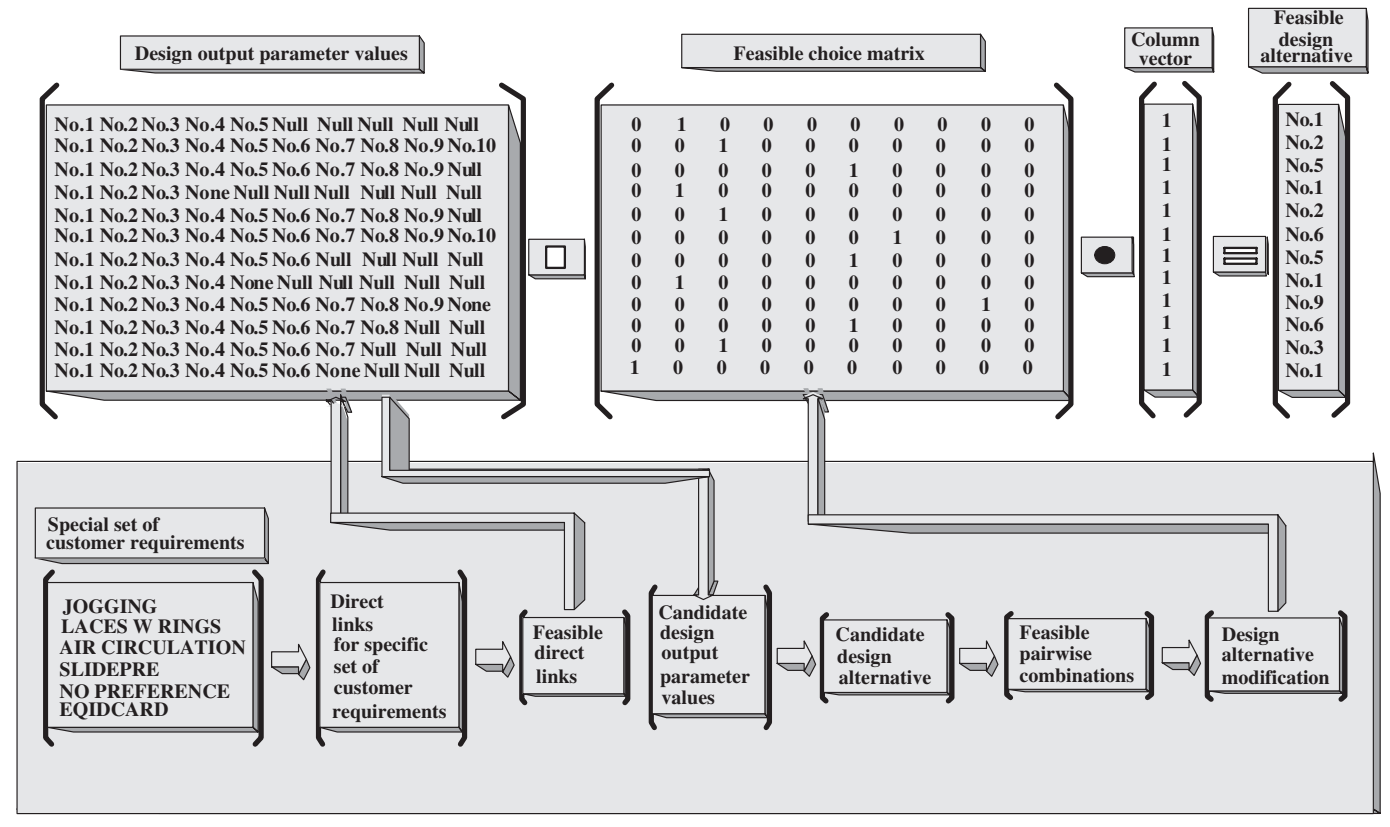

Figure 6. Procedures for the feasible choice matrix generation. 
feasible design alternatives. It may be possible to develop product design more efficiently by providing the product designer with a computer-assisted system, which can quickly generate many feasible design alternatives based on customer requirements.

The research effort described in this document developed procedures corresponding to the matrix approach for generating feasible design alternatives and eliminating infeasible design alternatives based on a specific set of customer requirements. A sport shoe design was used as an example to help explain the development of this procedure. The computer programs used in this process were written in Microsoft Visual Basic 6.0. Note that the relational database system concept was used throughout the procedure development.

The matrix approach presented here was successfully applied to the customer-oriented product design for application areas as varied as ball point pens, clothing, electric fans, mice, office chairs, and cell phones. Future studies shall focus on integrating the matrix approach with a graphic representation procedure using the Internet allowing more convenient design communication. In addition, a performance evaluation procedure is considered to help generate enough feasible design alternatives and assess the quality of the recommended designs.

These results provide designers with a useful way to generate feasible design alternatives for evaluation using design automation while still in the process of solving the design problem.

\section{Acknowledgments}

The authors are grateful to the National Science Council, Taiwan for supporting this research under grant number NSC85-2213-E006-016. Gratitude is also extended to the reviewers and the Editor for their valuable comments.

\section{References}

1. Barton, J.A., Love, D.M. and Taylor, G.D. (2001). Design Determines $70 \%$ of Cost? A Review of Implications for Design Evaluation, Engineering Design, 12(1): 47-58.

2. Shehab, E.M. and Abdalla, H.S. (2001). An Integrated Prototype Systems for Cost-Effective Design, Concurrent Engineering: Research and Applications, 9(4): 243-256.

3. Bedworth, D.D., Henderson, M.R. and Wolfe, P.M. (1991). Computer-integrated Design and Manufacturing, New York: McGraw-Hill.

4. Huang, G.Q. and Mak, K.L. (2001). Web-Integrated Manufacturing: Recent Developments and Emerging Issues, Computer Integrated Manufacturing, 14(1): 3-13.

5. Tay, F.E.H. and Gu, J. (2002). Product Modeling for Conceptual Design Support, Computers in Industry, 48(2): 143-155.
6. Prasad, B. (1996). Concurrent Engineering Fundamentals: Integrated Product and Process Organization, Vol. I, New Jersey: Prentice Hall.

7. Chen, Y.H., Wang, Y.Z. and Wong, M.H. (2001). A WebBased Fuzzy Mass Customization System, Manufacturing Systems, 20(4): 280-287.

8. Mousavi, A., Adl, P., Gunasekaran, A. and Mirnezami, N. (2001). Customer Optimization Route and Evaluation (CORE) for Product Design, Computer-Integrated Manufacturing, 14(2): 236-243.

9. Chen, C.H., Khoo, L.P. and Yan, W. (2002). Web-Enabled Customer-Oriented Product Concept Formation Via Laddering Technique and Kohonen Association, Concurrent Engineering: Research and Applications, 10(4): 299-310.

10. Ulrich, K.T. and Eppinger, S.D. (2003). Product Design and Development, 3rd edn, New York: McGraw-Hill, Inc.

11. Aoussat, A., Christofol, H. and Coq, M.L. (2000). The New Product Design: A Transverse Approach, Engineering Design, 11(4): 399-417.

12. Beakley, G.C. and Chilton, E.G. (1973). Design: Serving the Needs of Man, New York: Macmillan Publishing Co., Inc.

13. Jones, C.J. (1992). Design Methods: Seeds of Human Futures, 2nd edn, New York: John Wiley \& Sons, Ltd.

14. Pahl, G. and Beitz, W. (1996). Engineering Design: A Systematic Approach, New York: Springer-Verlag, Ltd.

15. Tseng, M.M. and Jiao, J. (1998). Computer-Aided Requirement Management for Product Definition: A Methodology and Implementation, Concurrent Engineering: Research and Applications, 6(2): 145-160.

16. Cohen, L. (1995). Quality Function Deployment: How to Make QFD work for You, Reading: Addison-Wesley.

17. Suh, N.P. (2001). Axiomatic Design, New York: Oxford University Press.

18. Jiao, J. and Zhang, Y. (2005). Product Portfolio Identification Based on Association Rule Mining, Computer-Aided Design, 37(2): 149-172.

19. Prasad, B. (2000). A Concurrent Function Deployment Technique for a Workgroup-Based Engineering Design Process, Engineering Design, 11(2): 103-119.

20. Cross, N. (2000). Engineering Design Methods: Strategies for Product Design, 3rd edn, Chichester: John Wiley \& Sons.

21. Goldman, J. and Leonard, M.S. (1982). Component Design Strategy Permits Selection of Most Suitable Hospital Information System, Industrial Engineering, 14(2): 56-64.

22. Fabbri, T. and Schwab, A.R. (1992). Practical Database Management, Boston: PWS-KKENT.

23. Silberschatz, A., Korth, H.F. and Sudarshan, S. (2002). Database System Concepts, 4th edn, New York: McGraw-Hill.

24. Howard, R.A. (1971). Dynamic Probabilistic Systems, Volume I: Markov Models, New York: John Wiley \& Sons.

25. Staros, A. and Schwartz, R.S. (1988). Custom Footwear: The Role of Computer-Aided Engineering, Testing and Evaluation, 16(4): 417-420.

26. Nike Sport Research Laboratory (1983). Rear Foot Control, Cushioning and Shoe Design, Nike Research Newsletter, NH 03833.

27. Frederick, E.C. (1984). Physiological and Ergonomics Factors in Running Shoe Design, Applied Ergonomics, 15(4): 281-287.

28. Bunch, R.P. (1988). Foot Measurement Strategies for Fitting Athletes, Testing and Evaluation, 16(4): 407-411. 


\section{Ming-Chyuan Lin}

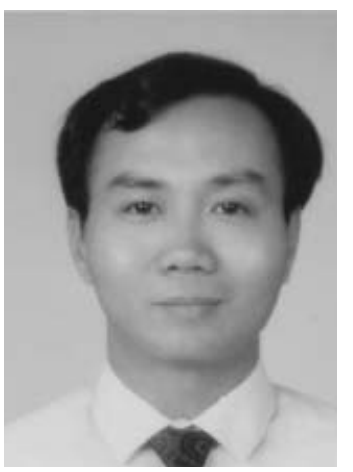

Ming-Chyuan Lin is currently an associate professor in the Department of Industrial Design at National Cheng Kung University, Taiwan. He received his BSE in Industrial Design from National Cheng Kung University and MS and $\mathrm{PhD}$ in Industrial Engineering from the University of Missouri-Columbia, respectively. His research interests are human factors engineering and computer-integrated design and manufacturing systems.

\section{Lung-An Chen}

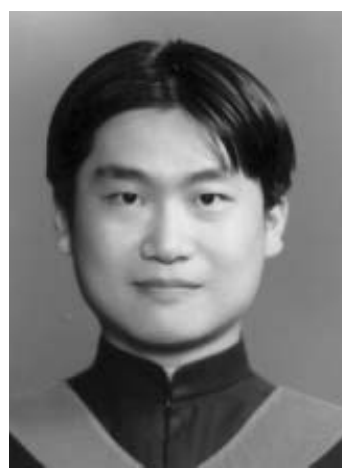

Lung-An Chen is currently a $\mathrm{PhD}$ candidate in the Department of Industrial Design at the National Cheng Kung University, Taiwan. He received his BS in Industrial Design from Da Yeh University, Taiwan and his MS in Industrial Design from National Cheng Kung University, Taiwan, respectively. His research interests are computer graphics, computer-aided design, product design and ergonomics. 